\title{
Money Supply and Time Deposits, 1914-69
}

N SEPTEMBER 1964 an article in this Review discussed the relation between money supply, time deposits, money plus time deposits, and periods of national economic contraction and expansion. In particular, the historical data were reviewed in light of the bypothesis that an increase in growth of the money supply or some other specific monetary magnitude, relative to growth of the demand for it, would result

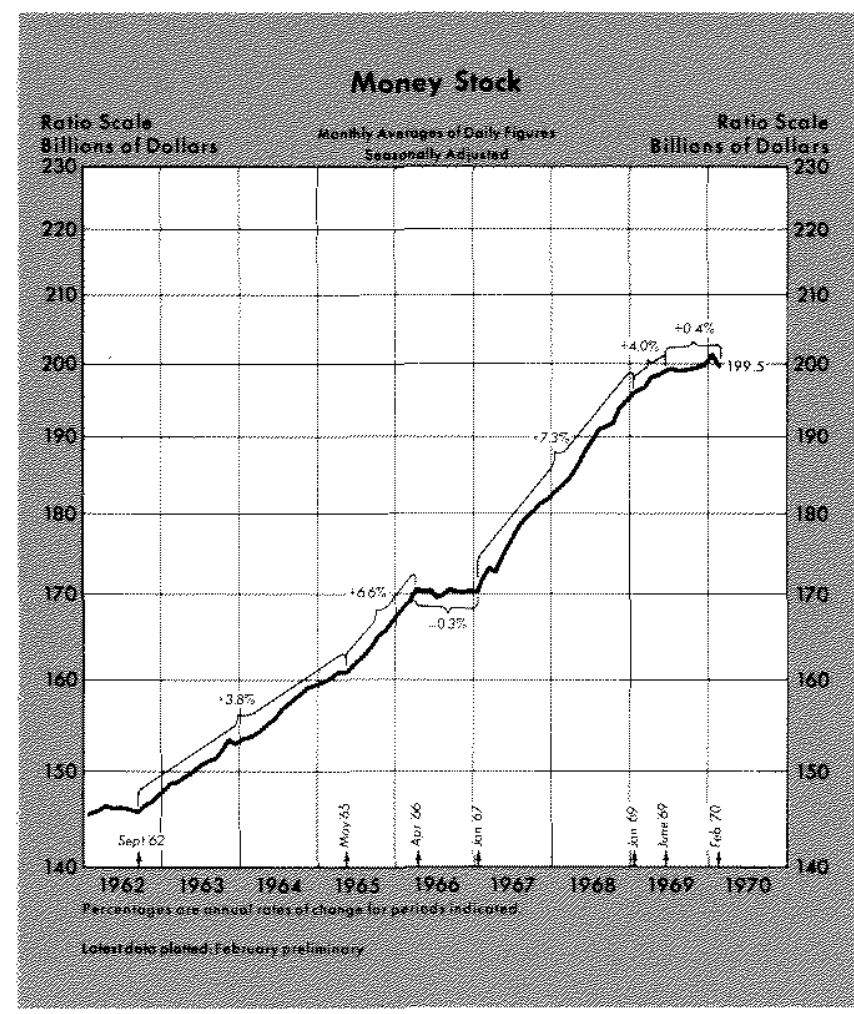

in a rise in total spending. Conversely, a reduction in the growth of this key variable, without a corresponding decline in the growth of demand for it, would cause a decline in spending.

This note, with accompanying charts and tables, re-evaluates the earlier conclusions in light of the additional experience since September 1964. The top tier of the chart on pages 8 and 9 shows weighted month-to-month changes in the stock of money, defined as private demand deposits plus currency held by the public, expressed in compounded annual rates of growth or contraction from August 1914 through December 1969. The middle and bottom tiers show

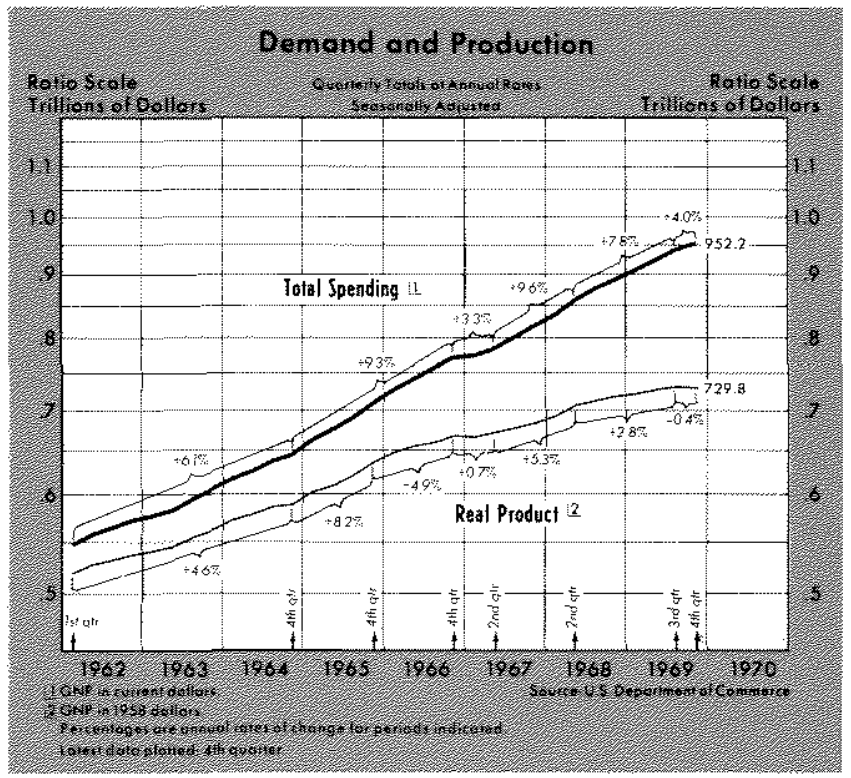




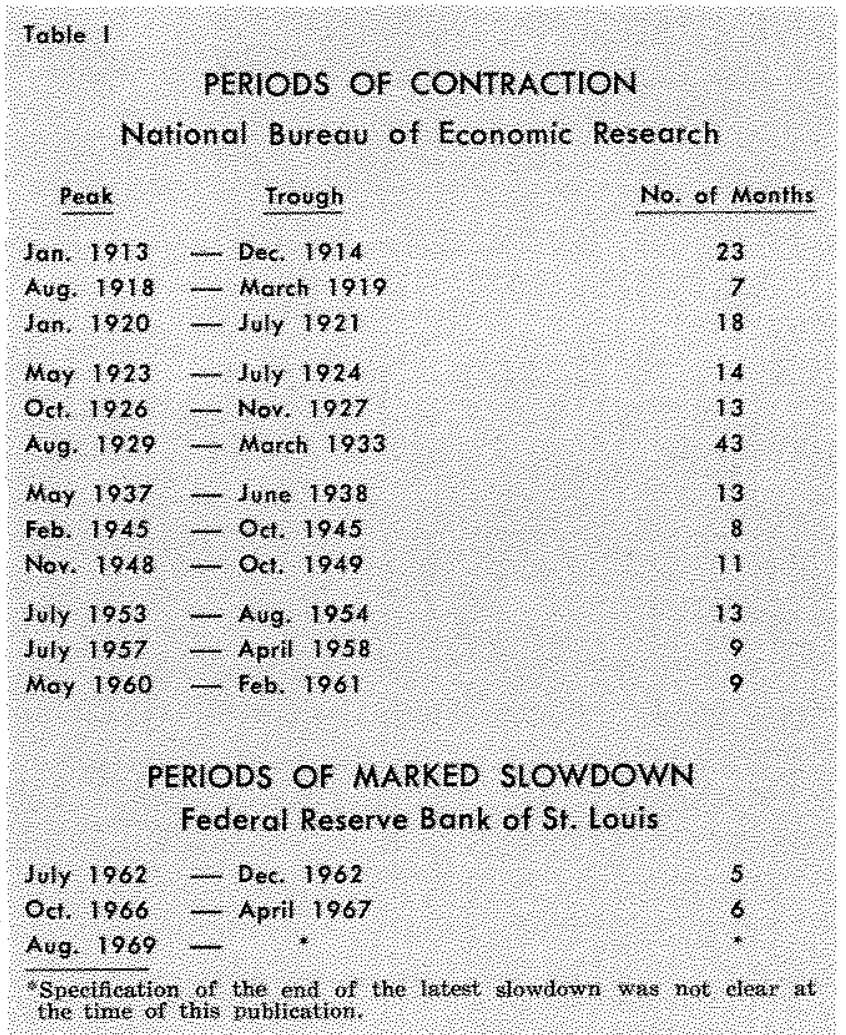

similar data for time deposits and money plus time deposits, respectively. The shaded vertical columns on the chart, 1914-1961, denote periods of economic contraction as determined by the National Bureau of Economic Research, and the shaded vertical columns, 1962-1969, denote periods of economic slowdown as selected by this bank. The initial and terminal dates for all but the current slowdown are presented in Table I. The horizontal bars on the chart represent the trend rates of change for periods of no marked and sustained change in the rates of change of the variable. Although selection of periods is judgmental, it is believed that most analysts would arrive at substantially similar results. The average annual rate of change for each selected period is presented in Table II for money, in Table III for time deposits, and in Table IV for money plus time deposits.

Experience since 1964 has been similar to that in the 1914-64 period. That is, marked and sustained changes in the rates of growth in either money or money plus time deposits have usually been followed after a brief lag by changes in the same direction in the growth of total spending. With respect to the hypothesis tested, this would seem to indicate that increases and decreases in the supply of these magnitudes, rather than being in response to changes in the

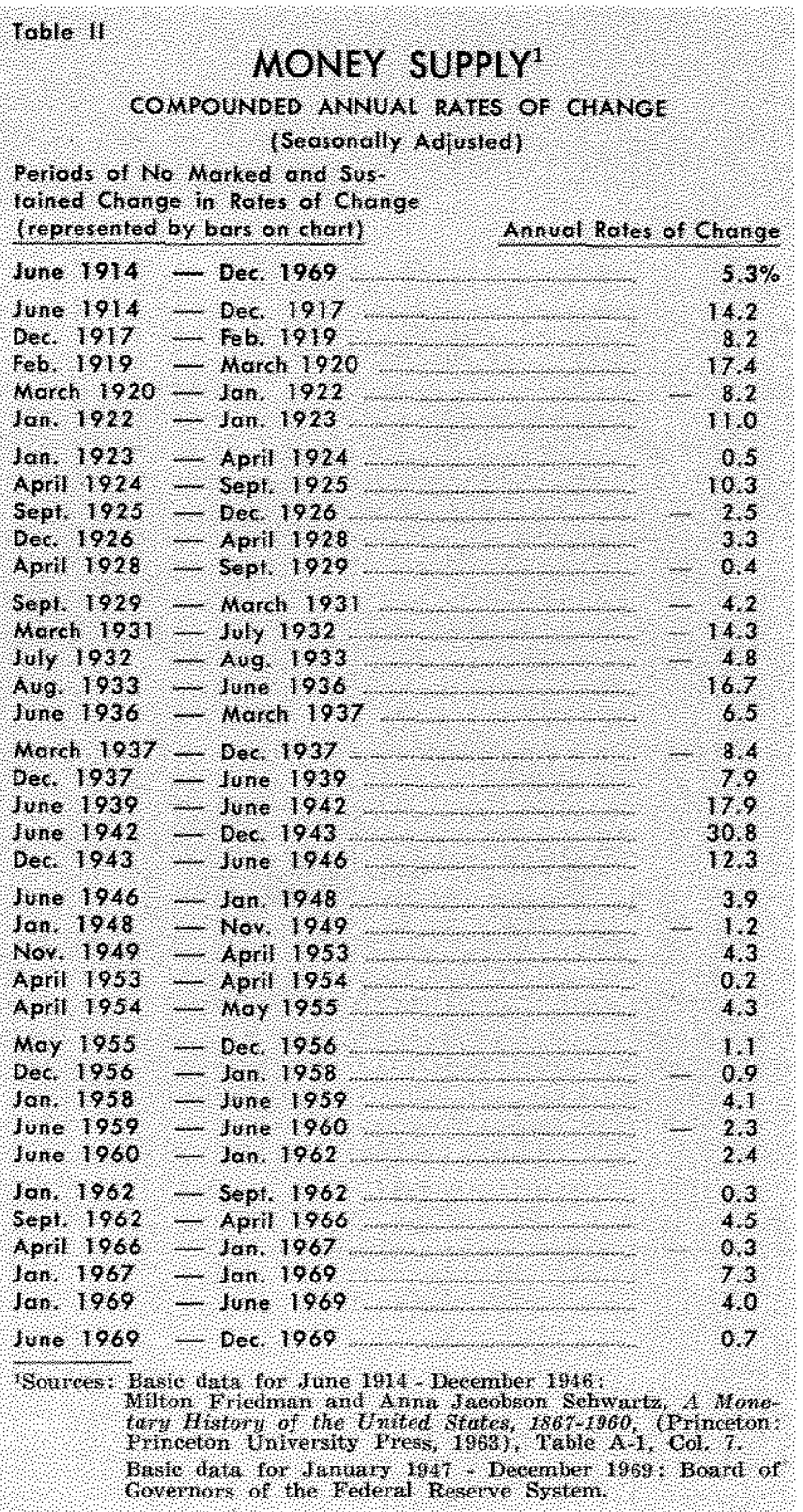

demand for them, have contributed to significant corresponding economic expansions and contractions. ${ }^{1}$

The growth rates of both money and money plus time deposits have generally declined prior to peaks in business activity and have risen before troughs. As shown in the two-page chart, the average rates of growth of money and money plus time deposits declined prior to the 1967 hesitation in economic activ-

\footnotetext{
ISimilar conclusions have been reached using more sophisticated statistical methods. See Leonall Andersen and Terry Iordan, "Monetary and Fiscal Actions: A Test of Their Relative Importance in Economic Stabilization", this Revieto, November 1968, pp. 11-24; and Michael Keran, "Monetary" and Fiscal Influences on Economic Activity - The Historical Evidence," this Review, November 1969, pp. 5-24, and "Monetary and Fiscal .... The Foreign Experience," this Review, February 1970 , pp. 16-28.
} 


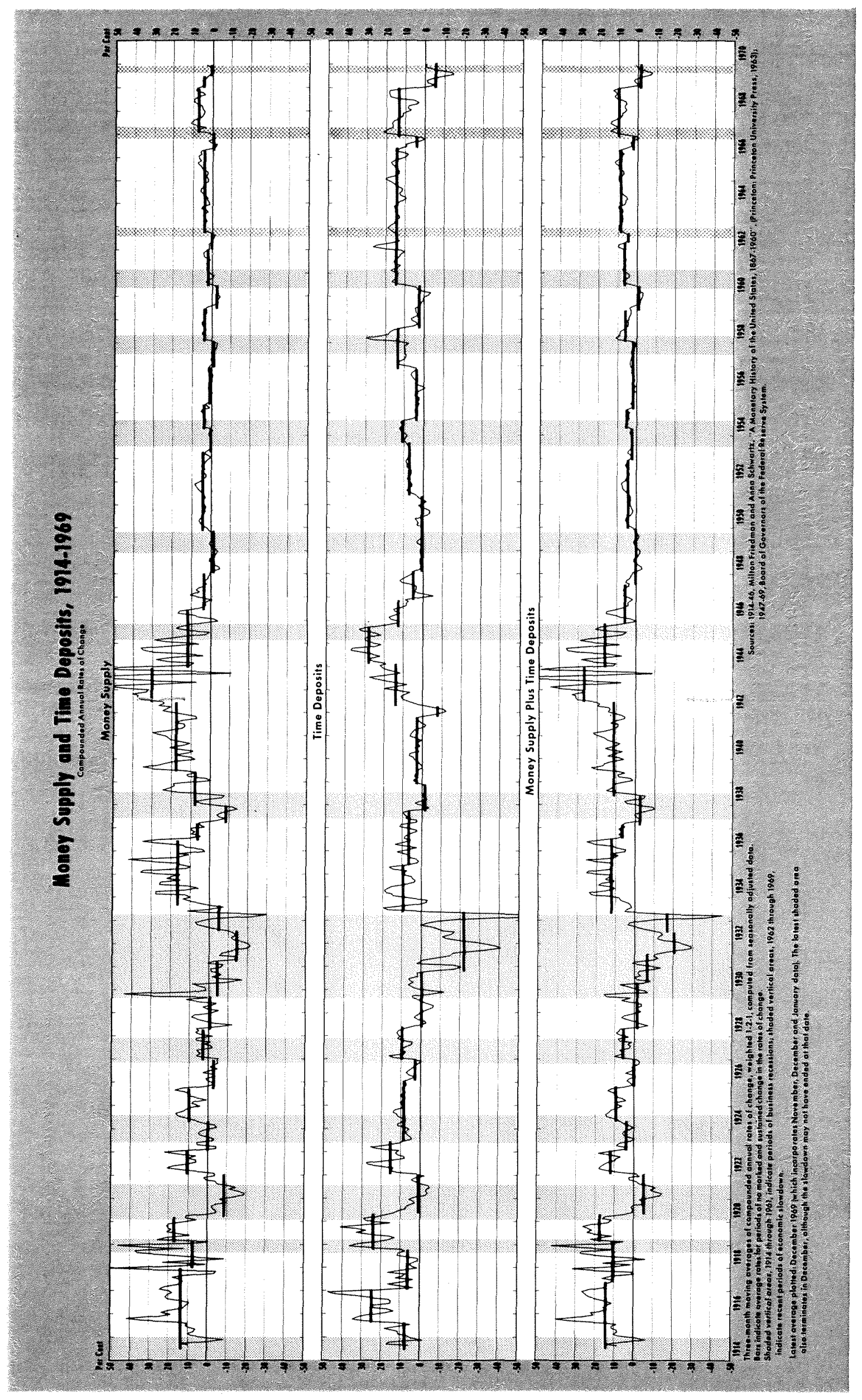

: 


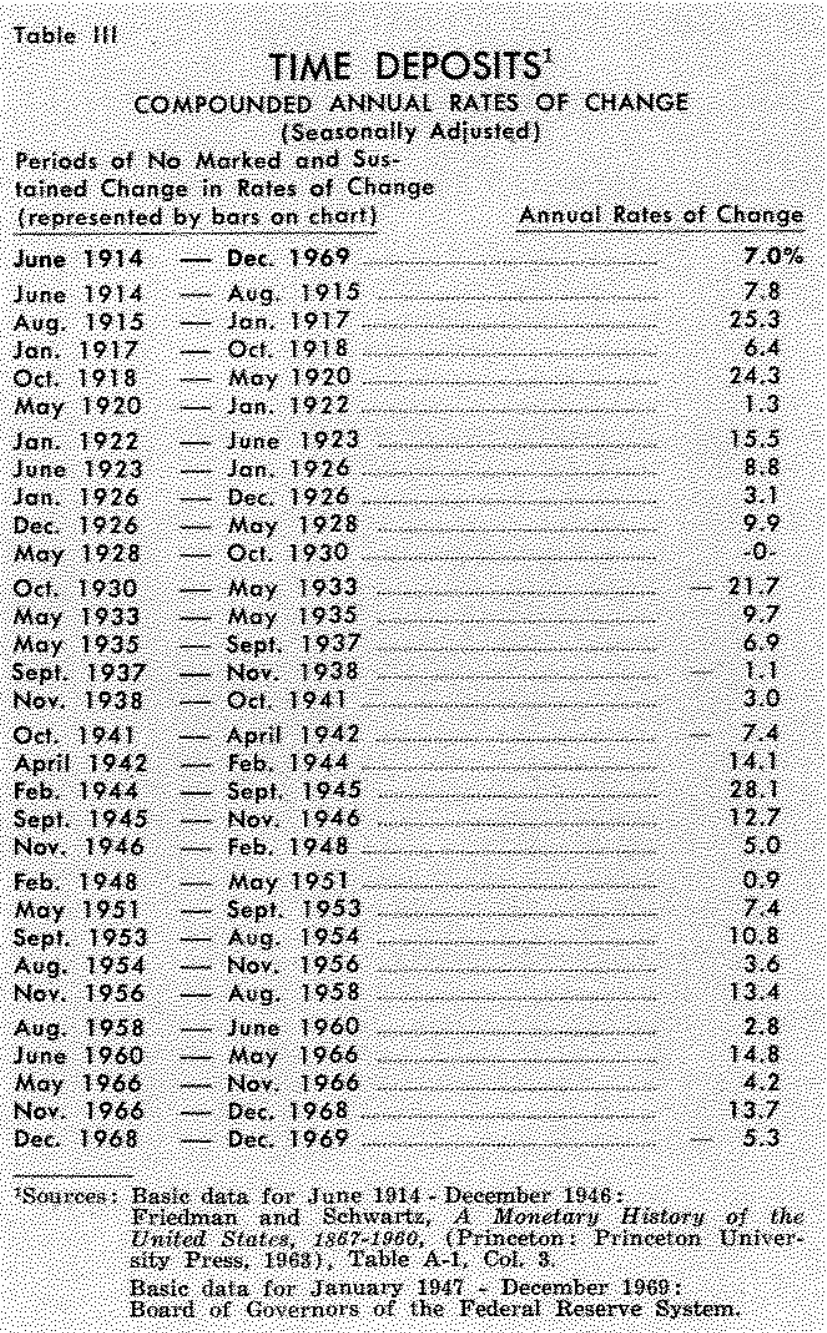

ity. This slowdown in economic activity, although marked, was not severe enough to be classed as a recession by the National Bureau of Economic Research. The average rate of change for both money and money plus time deposits rose prior to the rapid increase in total spending, which began in the sum. mer of 1967.

Movements in both money and money plus time deposits since 1914 have been broadly consistent with the hypothesis. However, when two variables are both consistent with a hypothesis, it is appropriate to ask which shows the most consistency in accord with that hypothesis. In this instance, the money stock, exclusive of time deposits, appears to be the better key variable. For example, beginning in November 1956 , eight months before a business cycle peak, time deposits rose rapidly. In fact, in many instances since 1914, time deposits did not decline before a peak

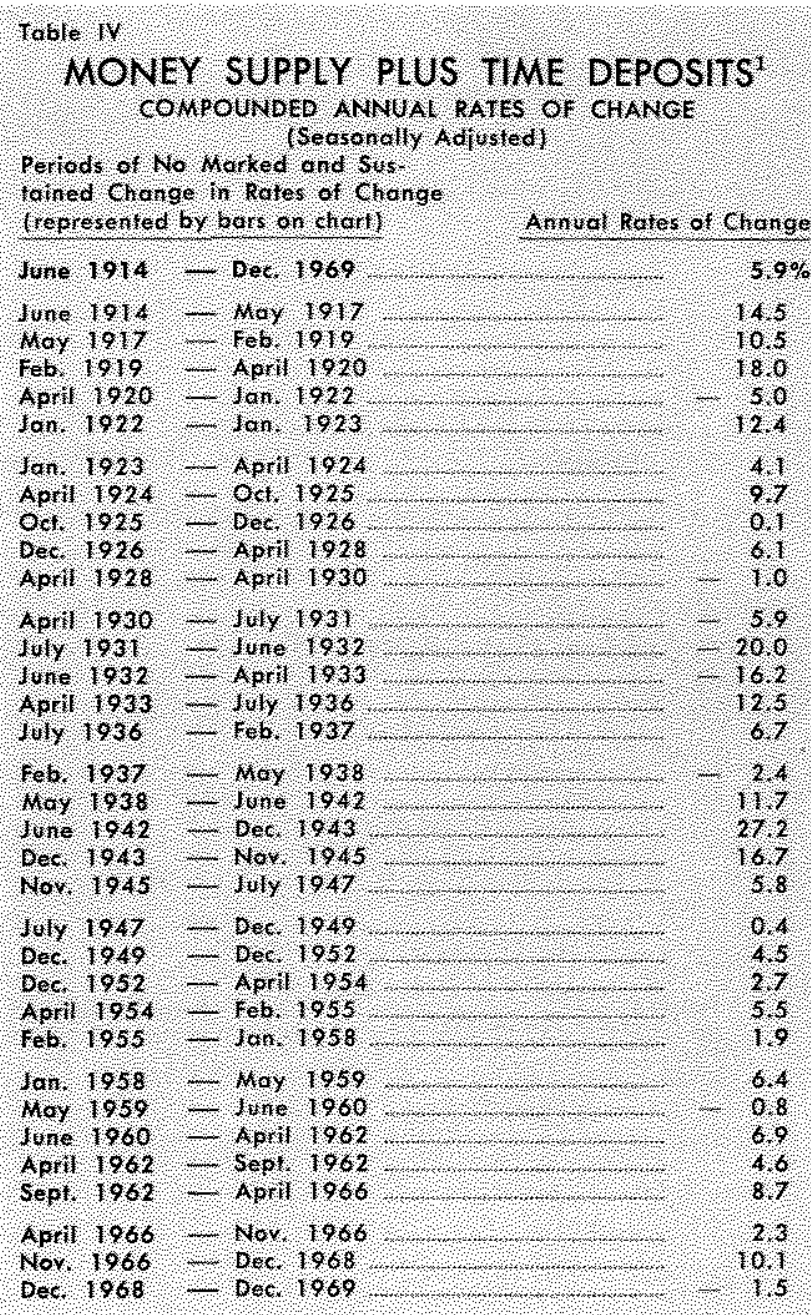

Sonrees bayic data for June 1914 December 1946

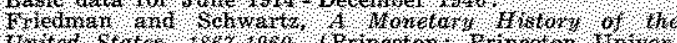

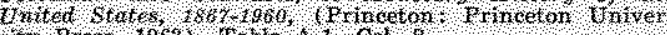
Sty Pres, 186 ) Table $1,1, \mathrm{Col} 8$

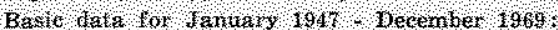

Brad of Govenors of the Federd Reserve Systen.

in business activity nor rise before a trough. Therefore, the consistent behavior of money plus time deposits results primarily from the overpowering strength of the money variation, rather than the contribution of time deposits. It follows that money plus time deposits is a less sensitive variable than the money supply alone. Moreover, the change in the rate of growth of time deposits has been seriously affected in recent years by the relation between Regulation $Q$ ceilings on interest rates banks are permitted to pay on time deposits and market interest rates. ${ }^{2}$ As a result, the relation between time deposit growth rates and changes in total spending has been even weaker since 1964 than in earlier years.

This article is avatlable as Reprint No. 54 . 